\title{
Neoplasias genitourinarias en trasplante renal
}

\author{
Genitourinary neoplasms in kidney transplantation \\ Fernando Gabilondo-Navarro* \\ * Departamento de Urología. \\ Instituto Nacional de Ciencias Médicas y Nutrición Salvador Zubirán.
}

El trasplante renal es el tratamiento de elección en pacientes con insuficiencia renal terminal, tiene mejor supervivencia y calidad de vida que la hemodiálisis o diálisis peritoneal. ${ }^{1}$ La inmunosupresión en el receptor, incrementa la frecuencia de cáncer y promueve el crecimiento de neoplasias en órganos sólidos. En la actualidad, con inmunosupresión más eficiente se incrementa la supervivencia del injerto y del paciente, ${ }^{2}$ en consecuencia aumentan las neoplasias genitourinarias.

Los receptores de trasplante renal (RTR) tienen un riesgo de tres a cinco veces mayor de cáncer que la población general y una mortalidad de $9-12 \%$, (Tabla $1)^{2,3}$ este incremento en la frecuencia se atribuye a una disminución de la vigilancia inmunológica, activación de virus oncogénicos, estimulación crónica del sistema inmunológico, inmunosupresión, tabaco, uremia. ${ }^{4}$

Con respecto a neoplasias genitourinarias, el cáncer renal es 15 veces más frecuente, el cáncer vesical es tres veces más frecuente que la población general; cáncer de próstata y testicular aún es controversial. ${ }^{5}$

La presencia de neoplasias malignas en RTR incrementa la mortalidad, por lo que es importante analizar la frecuencia, el diagnóstico temprano y la posibilidad de prevención. La historia familiar de cáncer renal requiere consulta genética.

El tabaquismo es un factor de riesgo importante en cáncer renal, vesical y de próstata.

\section{DONADOR}

Donador fallecido: si se puede hacer un estudio de ultrasonido renal o tomografía renal simple es aconsejable.
Donador vivo: si existe la sospecha de tumor renal sólido se debe efectuar biopsia renal pretrasplante. Si es cáncer renal de células claras bajo grado (Fuhrman 1) y único, se puede donar el riñón afectado y hacer la extirpación en el momento de la perfusión. Se deben enviar bordes quirúrgicos transoperatorios.

En caso de un tumor en grupo colectores o pelvis renal es una contraindicación absoluta para la donación renal, generalmente son carcinomas de células transicionales.

En mayores de 40 años, se debe medir el antígeno prostático específico (APE), sobre todo los que tengan antecedentes familiares de cánceres endócrinos (próstata, mama, ovario, útero).

\section{RECEPTOR. TRATAMIENTO}

\section{Cáncer renal}

En 1,256 RTR, 88 (7\%) pacientes desarrollaron neoplasia; de los cuales 18 (20.4\%) fueron genitourinarios (20.4\%). El más común fue cáncer renal con $38.8 \%{ }^{6}{ }^{6}$

Las neoplasias genitourinarias (GU) constituyen el $15.6 \%$ de todas las neoplasias malignas. El cáncer más frecuente en RTR es el cáncer renal de los riñones nativos, es 7-15 veces más frecuente que la población general. El cáncer renal en el injerto es de 0.19\%. (Tabla 2). ${ }^{7}$

- Ultrasonido renal de riñones nativos pretrasplante y posteriormente a los seis meses y cada año. Ante cualquier imagen sospechosa se debe realizar tomografía o resonancia magnética. 
- Tumores renales nativos: nefrectomía uni- o bilateral, laparoscópica de preferencia o abierta en algunos casos.

- En riñón trasplantado: si es posible en tumores $<4$ $\mathrm{cm}$ nefrectomía parcial o radical.

- En cáncer de células transicionales de grupos colectores o pelvis renal. Factores de riesgo: nefropatía por analgésicos o enfermedad de los Balcanes, tabaquismo. Tratamiento: nefroureterectomía, previa cistoscopia. ${ }^{8}$

Cáncer vesical-frecuencia de neoplasias genitourinarias $33.3 \%{ }^{6}$

- Cáncer vesical o de pelvis renal con síntomas urinarios irritativos (urgencia, polaquiuria) sin infección; general de orina, ultrasonido vesical, citologías urinarias sobre todo en presencia de hematuria.

- Hematuria: UROTAC con contraste, si es posible, cistoscopia.

- Cáncer vesical superficial o cáncer in situ: resección transuretral, biopsias profundas. Posibilidad de tratamiento BCG o mitomicina intravesical y vigilancia con cistoscopias, si es invasor, cistectomía radical y en casos seleccionados quimioterapia y radioterapia.

Cáncer de próstata-frecuencia

$12.5 \%$ de los genitourinarios ${ }^{6}$

- Tacto rectal indispensable a mayores de 40 años o con antecedentes de cánceres endócrinos (próstata, mama, ovario, útero), pretrasplante. Si el APE es < $1.0 \mathrm{ng}$, repetir cada dos años, si es cercano a $4 \mathrm{ng}$, repetir cada seis meses; $>4$ ng posibilidad de resonancia magnética multiparamétrica y/o biopsia.

Tabla 1: Epidemiología del cáncer en receptores de trasplante renal

\section{- Cáncer de novo = postrasplante 10 años 20 años \\ Más frecuencia que la población general \\ - Cáncer segunda causa de muerte a largo plazo \\ - Transmisión donador-receptor $0.02 \%$ \\ - Diálisis por más de 4 años 60-80\% con enfermedad multiquística renal adquirida}

Modificado de: Pérez-Sáez MJ, Canal C, Cofan F, Errasti P, Jimeno L, López-Oliva M et al. Epidemiología del cáncer en el trasplante renal: incidencia, prevalencia y factores de riesgo. Nefrología Sup Ext. 2018; 9 (1): 24-36. ${ }^{3}$
- Adenocarcinoma de próstata; depende del puntaje de Gleason, si es un Gleason < 7: vigilancia (poco estudiado); si es un Gleason > 7: prostatectomía radical, radioterapia. braquiterapia, radiofrecuencia o crioterapia.

\section{Cáncer de testículo-frecuencia de $6.25 \%^{6}$}

- Factores de riesgo: criptorquidia y testículo atrófico. Existe controversia si es más frecuente en RTR. Se recomienda exploración física del escroto y testicular en el pre- y postrasplante. Ante sospecha de tumoraciones, ultrasonido escrotal (testicular). Después del trasplante puede aparecer hidrocele del lado donde se colocó el injerto. Se debe efectuar ultrasonido testicular con cualquier aumento de volumen y cuando se sospecha de tumor, de-

Tabla 2: Neoplasias genitourinarias en receptores de trasplante renal.

- Cáncer renal. Riñones nativos de 7 a 10 veces más que en la población general

- La mayoría incidentales, bajo grado, bajo estadio

- Cáncer renal en el injerto $0.19 \%$ $50 \%$ papilares, bajo grado

- Cáncer próstata: 2 veces más: cirugía, braquiterapia, radioterapia HIFU

- Cáncer de vejiga 3 veces más: superficial cáncer in situ: BCG, mitomicina Invasor-cistectomía radical

- Cáncer pelvis renal: frecuencia de 0.7-3.8\%

- Cáncer de testículo: seminoma-radioterapia o quimio No seminomatosos-quimioterapia

Modificada de: Tillou X, Doerfler A. Urological tumors in renal transplantation. Minerva Urol Nefrol. 2014; 66 (1): 57-67. ${ }^{7}$

Tabla 3: Neoplasias genitourinarias en RTR, experiencia del Frankfurt Transplant Center.

- 1990 trasplantes $(1979-2009)$ Donador cadáver $85 \%$, vivo $11.6 \%$

- 374 pacientes, 423 cánceres $15.6 \%$ genitourinarios

- 66 genitourinarios en 58 pacientes (44 hombres, 14 mujeres)

- Cáncer renal 29

- Cáncer de células transicionales $26 \quad 5$ injerto ren 20 vejiga

- Cáncer próstata: 11 6 pelvis renal

- Cáncer testículo: 2-3 veces más frecuente

- Mortalidad general $44 \%$

Modificado de: Tsaur I, Karalis A, Probst M, Blaheta RA, Scheuermann EH, Gossmann J et al. Development of urological cancers in renal transplant recipients: 30-year experience at the Frankfurt Transplant Center. Cancer Sci. 2010; 101 (11): 2430-2435. ${ }^{9}$ 
terminar marcadores tumorales (alfafetoproteína, unidad $\beta$ de gonadotrofina, deshidrogenasa láctica).

- Estirpes histológicas, la más frecuente, seminoma: orquiectomía radical, radioterapia o quimioterapia.

- No seminomatosos: orquiectomía radical y, dependiendo de la extensión, linfadenectomía retroperitoneal y/o quimioterapia.

\section{CÁNCER DE PENE}

- Frecuencia $6.3 \%{ }^{10}$ de células escamosas, factor de riesgo virus de papiloma humano en genitales: dependiendo de la extensión, cirugía local, láser o radical.

\section{REFERENCIAS}

1. Maglakelidze N, Pantsulaia T, Tchokhonelidze I, Managadze L, Chkhotua A. Assessment of health-related quality of life in renal transplant recipients and dialysis patients. Transplant Proc. 2011; 43 (1): 376-379.

2. Gondos A, Döhler B, Brenner H, Opelz G. Kidney graft survival in Europe and the United States: strikingly different long-term

3. Pérez-Sáez MJ, Canal C, Cofan F, Errasti P, Jimeno L, LópezOliva $\mathrm{M}$ et al. Epidemiología del cáncer en el trasplante renal: incidencia, prevalencia y factores de riesgo. Nefrología Sup Ext. 2018; 9 (1): 24-36. outcomes. Transplantation. 2013; 95 (2): 267-274.

4. Stewart JH, Vajdic CM, van Leeuwen MT, Amin J, Webster AC, Chapman JR et al. The pattern of excess cancer in dialysis and transplantation. Nephrol Dial Transplant. 2009; 24 (10): 3225-3231.

5. Kasiske BL, Snyder JJ, Gilbertson DT, Wang C. Cancer after kidney transplantation in the United States. Am J Transplant. 2004; 4 (6): 905-913.

6. Ochoa-López JM, Gabilondo-Pliego B, Collura-Merlier S, Herrera-Cáceres JO, de Zavaleta MS, Rodríguez-Covarrubias FT et al. Incidence and treatment of malignant tumors of the genitourinary tract in renal transplant recipients. Int Braz J Urol. 2018; 44 (5): 874-881.

7. Tillou X, Doerfler A. Urological tumors in renal transplantation. Minerva Urol Nefrol. 2014; 66 (1): 57-67.

8. Campistol JM, Morales JM. Manejo de tumores tras el trasplante renal. Nefrología. 2009; 29 (Sup. Ext. 2): 33-45.

9. Tsaur I, Karalis A, Probst M, Blaheta RA, Scheuermann EH, Gossmann J et al. Development of urological cancers in renal transplant recipients: 30-year experience at the Frankfurt Transplant Center. Cancer Sci. 2010; 101 (11): 2430-2435.

10. Besarani D, Cranston D. Urological malignancy after renal transplantation. BJU Int. 2007; 100 (3): 502-505.

Correspondencia:

Dr. Fernando Gabilondo-Navarro

E-mail: fgab @quetzal.innsz.mx 